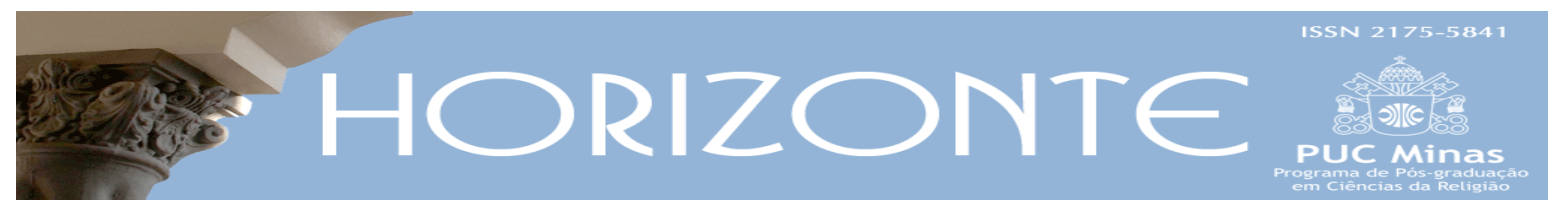

Dossiê: Ordens Religiosas Medievais: Poder e Sociedade - Artigo Original (c) $\underset{\mathrm{EY}}{\mathrm{i}}$

DOI - 10.5752/P.2175-5841.2017v15n48p1220

\title{
A Vida Religiosa feminina e as relações de poder na Ordem dos Pregadores: reflexões a partir do epistolário de Jordão da Saxônia
}

\author{
Religious Life of women and power relations in The Order of Preachers: \\ considerations about the Jordan of Saxony epistolary
}

\author{
Carolina Coelho Fortes * \\ Andreia Cristina Lopes Frazão da Silva **
}

\begin{abstract}
Resumo
Entre 1221 e 1236, Jordão da Saxônia, mestre geral da Ordem dos Frades Pregadores, e Diana de Andaló, monja do mosteiro de Santa Inês em Bolonha, foram assíduos correspondentes. Da troca de missivas que caracterizou sua amizade, chegaram até nós apenas algumas dezenas de cartas escritas pelo frade. Nelas é possível perceber o crescimento da Ordem naqueles primeiros anos de sua instituição, sua gradual organização, bem como as diretivas do mestre em relação à vida religiosa feminina, entre alusões aos detalhes da vida cotidiana de um religioso no século XIII. É neste corpus documental que nos apoiamos para compreender as relações de poder que pautaram o processo de institucionalização da então recém-criada Ordem dos Frades Pregadores, em especial a questão da afiliação de casas femininas, tema sobre o qual os frades oscilavam entre a resistência e a aceitação, por conta das implicações materiais e administrativas que tal associação significava. Concentraremos a nossa reflexão a partir da perspectiva da análise discursiva, em três cartas - duas enviadas à Diana, e uma enviada ao provincial da Lombardia, Estevão de Espanha-, para perceber as questões presentes na formação de um braço feminino da Ordem. Concluímos que esta discussão específica compunha um cenário maior de disputas internas pelo controle da Ordem.
\end{abstract}

Palavras-chave: Ordem dos Pregadores, Monasticismo feminino, Relações de poder

\begin{abstract}
Between 1221 and 1236, Jordan of Saxony, the general master of the Order of Friars Preachers, and Diana Anda ló, nun of the monastery of St. Agnes in Bologna, were frequent correspondents. From the exchange of epistles that characterized their friendship, only a few dozen letters written by the friar reached us. In them we can see the growth of the Order in those early years of its institution, its gradual organization as well as the policy of the master in relation to women's religious life, among allusions to the details of everyday life of a religious in the thirteenth century. It is in this documentary corpus that we support ourselves to comprehend the power relations which guided the process of institutionalization of the newly created Order of Friars Preachers, specially the affiliation of women's houses, a subject on which the friars oscillated between resistance and acceptance, because of the material and administrative implications that such an association meant. We will focus, in the discursive analysis, in three cards - two sent to Diana, and one sent to the provincial of Lombardy, Stephen of Spain - to understand the issues involved in the formation of a women's branch of the Order. We can conclude that this specific discussion comprehended a much bigger cenary of internal disputes for the control of the Order.
\end{abstract}

Keywords: Order of Preachers, female monasticism, Power relations

Artigo submetido em 24 de agosto de 2016 e aprovado em 21 de dezembro de 2017.

* Doutora em História Social (UFRJ) e professora adjunta da UFF. País de origem: Brasil. E-mail: carolfortes@hotmail.com

** Doutora em História Social (UFRJ), professora titular da UFRJ e do PPG em História Comparada, bolsista Pq2 e Cientista de Nosso EstadoFaperj. País de origem: Brasil. E-mail: andreiafrazao@terra.com.br.

Horizonte, Belo Horizonte, v. 15, n. 48, p. 1220-1252, out./dez. 2017 - ISSN 2175-5841 


\section{Introdução}

Jordão da Saxônia, membro de primeira hora da então recém-criada Ordem dos Frades Pregadores e sucessor de Domingos de Gusmão no governo dos irmãos, provavelmente escreveu, durante a sua trajetória de vida, muitas cartas. Contudo, só 57 foram preservadas. Deste conjunto, 50 foram enviadas ao Mosteiro de Santa Inês, localizado em Bolonha, muitas das quais dirigidas a uma religiosa específica: Diana de Andaló. Quatro foram remetidas a monjas do mosteiro beneditino de Nossa Senhora de Oeren, mas em só uma delas é registrado o nome da destinatária, Maria. Dentre as outras três cartas restantes, duas tinham destinatários coletivos: toda a Ordem e os frades do convento de Saint-Jacques de Paris. Só uma delas foi dirigida a um irmão: Estevão de Espanha, quando este era provincial da Província da Lombardia. Nossa proposta principal, nesse artigo, é analisar algumas dessas cartas, enfatizando as relações de poder que marcaram o início da institucionalização da Ordem dos Pregadores.

A partir de três cartas elaboradas por Jordão da Saxônia: a remetida a Estevão de Espanha e duas enviadas diretamente à monja Diana de Andaló, nosso intuito é traçar reflexões sobre o tema da vida religiosa feminina entre os dominicanos, à luz das relações de poder estabelecidas no seio deste instituto. Como destaca Mercedes Pérez Vidal, a filiação à Ordem dos Pregadores e o estatuto jurisdicional diverso das monjas dominicanas, ao menos até meados do século XIII, "no han suscitado el mismo debate historiográfico que en el caso de otras órdenes, como el Císter" (2013, p. 135). Assim, objetivamos contribuir com tal discussão.

Ao longo de toda o período medieval, cartas foram produzidas e circularam, como atestam as diversas coletâneas preservadas. Há décadas os medievalistas têm se preocupado em estudá-las, ${ }^{1}$ por compreendê-las como testemunhos singulares, pois veiculam de maneira mais direta ideias e emoções e expressam a criatividade das pessoas no cotidiano. Como afirma Katherine Kong, "letters offer an invaluable

\footnotetext{
${ }^{1}$ Há uma ampla produção sobre o tema. Alguns desses trabalhos são listados na bibliografia final.
} 
window onto how premodern people conceived of the self, accepted and resisted socially determined positions, and, in some instances, tried to reshape them" (2010, p. 2).

As cartas, no medievo, tinham um caráter mais público do que privado, sendo constantemente lidas em voz alta para uma comunidade e/ou circulavam publicamente. ${ }^{2}$ Assim, além de meios de comunicação pessoal, funcionavam como uma espécie de noticiário e tinham, em alguns casos, a função de documento legal. Desta forma, eram o meio por excelência de formação da opinião pública, de registro de informações relacionadas ao cotidiano, de instrução sobre diversos temas e de questionamento a respeito de aspectos considerados relevantes para a sociedade que as produzia.

A importância social das cartas no medievo pode ser atestada pelo desenvolvimento da ars dictaminis ou ars dictandi, o estudo e a prática das composições epistolares. O manual de Alberico de Monte Cassino, o mais antigo conhecido, lista as cinco partes da carta que se tornaram padrão na Europa medieval: a salutatio, saudação ao destinatário, que cuidadosamente articula a sua posição social; o exordium ou benevolentiae captatio, que consiste em um provérbio ou citação da Bíblia, com a intenção de assegurar a boa vontade do receptor da mensagem; a narratio, que elucida o propósito específico da carta; a petitio, que suplica ao leitor a cumprir o que lhe é requisitado, e, por fim, a conclusio, que recapitula e conclui a missiva (CHEREWATUK \& WIETHAUS, 1993, p. 4-5).

Como destaca Richard McNabb, “essa adaptação da oração clássica se tornou o "formato aprovado" para os manuais epistolares" (MCNABB, 2004, p. 105).3 Contudo, por motivos diversos, nem todos seguiam de forma fiel as regras estabelecidas para a redação das epístolas. Neste sentido, há que se observar, como

\footnotetext{
${ }^{2}$ As cartas pessoais passam a existir apenas com o surgimento do vernáculo, e mesmo nesse caso os autores parecem conscientes de uma audiência além da imediata.

3 "this adaptation of the classical oration became the "approved format" for letter-writing manuals" (MCNABB, 2004, p. 105).
} 
propõe Derrida (2004), que uma carta é sempre escrita “em rasura”, pois está permeada por censuras internas, além das externas.

O gênero epistolar é também dialógico, pois, por um lado, o destinatário é sempre onipresente no texto e, por outro, autor e receptor estão inseridos em uma dada conjuntura. Tais elementos influenciam a forma e o conteúdo das cartas e a representação do seu emissor. Por isso, as informações sobre o remetente podem ser tanto uma máscara quanto um retrato honesto, da mesma forma que seu conteúdo pode ser tanto uma ponte de ligação entre as duas partes quanto uma barreira propositadamente erigida (ALTMAN, 1982, p. 200). O mesmo podemos afirmar da percepção do contexto no texto, que pode ser referenciado, pressuposto, ignorado ou reinventado.

Para a análise das missivas selecionadas, partimos da concepção de poder proposta por Foucault: o poder não é unificado, não é coerente e não se encontra centralizado. Como sintetiza o filósofo, “o poder não é uma instituição, e nem uma estrutura, nem tampouco uma certa força que incorporamos. O poder é o nome que atribuímos a uma situação estratégica complexa numa determinada sociedade” (FOUCAULT, 1999, p. 90). Desta forma, em nossa análise, buscamos realçar os elementos textuais que sublinham a complexidade das relações sociais em sua dimensão micro, interpessoal. Assim, não propomos uma leitura literal de tais materiais, mas uma análise que esteja atenta não só ao que é relatado, mas como o é, bem como ao não dito e aos eventuais subentendidos. Em particular nos interessam os mecanismos textuais utilizados para a imposição de autoridade, tais como exortações, tensões, hierarquizações, negociações e consensos.

\section{Os atores: o remetente e os destinatários}

Para a construção de uma biografia de Jordão da Saxônia possuímos, além de seus próprios escritos, diversos documentos diretos e indiretos, tais como as cartas que recebeu, as Vitae Fratrum, as atas dos Capítulos Gerais, entre outros textos. 
Contudo, como tais materiais são lacunares, muitos aspectos de sua trajetória são desconhecidos e alvo de debates.

Jordão nasceu por volta de 1185, na região de Westpfalia. Sobre a sua infância pairam diversas dúvidas. A documentação apresenta dados mais precisos a partir de seu estabelecimento em Paris, para estudar, em cerca de 1209. Dez anos mais tarde, naquela mesma cidade, ele conheceu Domingos de Gusmão e entrou para a Ordem. A essa altura, Jordão já era Mestre em Artes, Bacharel em Teologia e havia sido ordenado diácono. Passou, então, a viver no convento de Saint Jacques de Paris. Em 1220, o dominicano participou do Primeiro Capítulo Geral da Ordem, que foi realizado em Bolonha. Nesta reunião ele foi incumbido da tarefa de explicar as Sagradas Escrituras aos frades de seu convento. Alejandro del Cura supõe que nesta mesma ocasião ele teria começado a pregar aos estudantes parisienses (1984, p. 13).

Em 1221, Jordão participou do Segundo Capítulo Geral da Ordem, também reunido em Bolonha. Nesta assembleia, ele foi nomeado como o primeiro provincial da Lombardia, passando a residir em Bolonha. Contudo, permaneceu pouco tempo no cargo, já que, com a morte de Domingos, foi eleito Mestre Geral no Terceiro Capítulo, reunido em Paris em 1222.

Um dos primeiros atos de Jordão como dirigente da Ordem dos Pregadores foi a fundação do convento feminino de Santa Inês de Bolonha, dando prosseguimento ao trabalho iniciado por Domingos, tema que abordaremos a seguir. Neste sentido, em 26 de junho de 1223, cinco mulheres, dentre as quais Diana de Andaló, ingressaram na vida religiosa dominicana em uma cerimônia presidida pelo Mestre Geral. É provável que a relação de amizade entre Diana e Jordão, evidenciada pelas cartas, tenha se estabelecido nesta ocasião.

Durante os 15 anos em que foi Mestre Geral, Jordão, além de desenvolver atividades de pregação em diversas cidades, esteve envolvido com a organização institucional da Ordem dos Pregadores. Dentre outros assuntos, teve que lidar com a já citada questão da filiação de mulheres à Ordem, da regulação do estudo nos 
conventos, a trasladação e canonização de Domingos e a presença dos frades como docentes nas Universidades. Em 1237, a caminho da Província Dominicana da Terra Santa, a embarcação em que estava naufragou, ocasionando a morte do Mestre Geral.

Sobre Diana de Andaló também existem alguns testemunhos dispersos. Além das cartas enviadas por Jordão, há documentos do convento de Santa Inês, a epígrafe colocada sob seu túmulo e uma vita, composta por uma irmã da comunidade, entre 1264 a 1283. Esses documentos informam que Diana nasceu em 1201 na cidade de Bolonha, no seio da família nobre dos Carbonesi. Andaló deriva do diminutivo do nome de seu pai, André, que foi usado por seus descendentes.

Segundo apontam os documentos, Diana começou a se interessar pelo modo de vida dominicano ao ouvir uma pregação de Frei Reginaldo, professor de direito canônico da Universidade de Paris, que visitou Bolonha a convite de Domingos em 1218. A jovem estabeleceu então um diálogo com o Fundador, que teria aprovado o seu desejo de ingressar na ordem e recebeu, em uma cerimônia solene, mas reservada, o seu compromisso de viver como religiosa junto com outras quatro jovens. 4

Apesar dos esforços de Domingos em estabelecer um convento feminino em Bolonha, tal plano enfrentou dificuldades, pois suscitou a oposição dos familiares das mulheres e do bispo da cidade. Como alternativa, Diana e suas companheiras, 5 em 1221, buscaram refúgio no eremitério de Ronzano, uma comunidade de cônegos regulares, localizado próximo a Bolonha. Contudo, como também destacam os testemunhos, seus parentes a retiraram a força deste local e a mantiveram presa em casa por quase um ano. Após a morte de Domingos, ocorrida em 1222, Diana voltou para Ronzano, mas desta vez não foi resgatada por sua família.

\footnotetext{
${ }^{4}$ Seguimos, aqui, a cronologia dos acontecimentos proposta por Alessandrini (1961, p. 48-50).
}

${ }^{5}$ Segundo Alberzoni, Diana só reuniu um grupo de companheiras posteriormente (2010, p. 7). 
Como já assinalado, Jordão foi o responsável por levar adiante o projeto de Domingos, fundando o mosteiro de Santa Inês de Bolonha, consagrado em 1223. Logo ingressaram ali Diana e suas companheiras saídas de Ronzano, a quem se juntaram quatro irmãs de São Sisto de Roma, outra comunidade feminina vinculada aos dominicanos. Uma delas, a irmã Cecília de Roma, da nobre família dos Cesarini, ocupou o cargo de priora do convento.

Como é possível constatar pelas cartas preservadas, Jordão, enquanto viveu, prestou assistência espiritual a toda a comunidade de Santa Inês, mas, sobretudo, a Diana, pela qual nutriu uma especial amizade, como indicam as muitas missivas que lhe foram enviadas. ${ }^{6}$ Durante sua vida religiosa, a monja enfrentou, juntamente com suas irmãs do convento, o ataque a sua cidade pelo Imperador Frederico II, momentos de penúria e a discussão sobre o direito das irmãs participarem da Ordem dos Pregadores. Ela faleceu em 1236, sendo sepultada no mosteiro pelo qual tanto lutou.

Sobre Estevão da Espanha possuímos, além das cartas, as atas de Bolonha do processo de canonização de Domingos e outros documentos diretos e indiretos. Natural da Península Ibérica, é provável que tenha conhecido pessoalmente Domingos em Roma, um ano antes de seu ingresso na Ordem (GELABERT, MILAGRO, GARGANTA, 1947, p. 246). Contudo, é possível que ele tenha ouvido sobre a fama do Fundador quando ainda residia na Hispania.

Estevão era estudante de Direito canônico na Universidade de Bolonha quando decidiu, em 1218, ingressar na Ordem dos Pregadores. Como frade, ele participou do Primeiro Capítulo Geral da Ordem, em 1220, tal como Jordão. Também como Jordão, foi eleito provincial da Lombardia. Quanto ao período exato durante o qual ocupou o cargo, há controvérsias. Para alguns ele foi escolhido para a função em 1224 e, para outros, só em 1227 (GELABERT, MILAGRO, GARGANTA,

\footnotetext{
${ }^{6} \mathrm{O}$ tema da amizade foi desenvolvido entre os cistercienses no século XII e, no século XIII, se expandiu para outros grupos religiosos. Sobre o tema ver, dentre outros, MCEVOY (1981); BYNUM (1982); HASELDINE (1993); KELLY (2004). Para uma abordagem desenvolvida no Brasil, ver PEREIRA (2013).
} 
1947, p. 236). De qualquer forma, seja o primeiro ano de seu governo 1224 ou 1227 , ele foi nomeado quando Jordão da Saxônia já era Mestre Geral e, certamente, estava ciente da existência de uma comunidade de mulheres religiosas que se considerava vinculada à Ordem dos Pregadores na província sob sua direção.

Estevão teve papel de destaque na promoção do traslado e canonização de Domingos, processo no qual foi uma das testemunhas. Talvez por isto tenha se aproximado do papa Gregório IX, que o consagrou como arcebispo de Oristano, localizado na Ilha de Sardenha. A data de sua morte é desconhecida.

Estas três pessoas, apesar de suas diferenças de origem geográfica, sexo, educação, etc., tiveram suas trajetórias unidas pela vinculação à Ordem dos Frades Pregadores. Ali, desempenharam papéis diferentes e lutaram por interesses distintos, evidenciando as tensões internas à Ordem. Consideramos que essas tensões ficam mais explícitas nas cartas de Jordão do que em qualquer outro registro dominicano do período. Neste sentido, questionamos o que tais cartas nos revelam sobre as relações de poder entre esses religiosos e suas ideias sobre a filiação de conventos femininos aos irmãos pregadores.

\section{2 epistolário de Jordão da Saxônia}

Como já afirmamos na introdução, Jordão certamente escreveu muitas cartas ao longo de sua vida. Sobretudo porque, como Mestre Geral da Ordem, encontravase constantemente em viagem e precisava zelar por todo o grupo de irmãos, mesmo à distância. No entanto, só conhecemos de sua lavra 57 cartas.

Os autógrafos de Jordão perderam-se, mas as cartas foram transmitidas por diferentes cópias manuscritas guardadas, principalmente, em Roma e Wurzburg (GEORGES, 1933, p. viii). Infelizmente não encontramos uma listagem completa de 
tais códices.7 $\mathrm{O}$ epistolário preservado foi publicado pela primeira vez por Ceslaus Bayonne, O.P., em latim e francês, em 1865. Em 1881, Berthier, O.P., incluiu o texto latino das cartas em uma edição dos escritos de Jordão da Saxônia, intitulada The First Beginnings of the Order of Preachers. Em 1924, Marguerite Aron publicou uma tradução francesa das missivas e, no ano seguinte, Altaner preparou uma nova edição do texto latino. Em 1927, Mumbauer, O.P., lançou uma tradução para o alemão. Uma versão em inglês das cartas foi incluída por Norbert Georges em sua obra Blessed Diana and Blessed Jordan of the Order of Preachers. The Story of a Holy friendship and a successful spiritual direction, de 1933. Outra tradução para o inglês, preparada por Gerald Vann, O.P., foi publicada em 1960 e reeditada em 2006. Em 1984, Alejandro del Cura, O.P., verteu as cartas para o espanhol. Duas traduções para o português da edição espanhola foram preparadas por Alexandre F. Magalhães e Filipe Rodrigues, O.P. Para a elaboração deste artigo utilizamos diversas edições, mas optamos por transcrever as cartas a partir da preparada por Rodrigues, lançada em 2014 .

A cronologia das cartas de Jordão ainda é bastante incerta, já que nenhuma é datada e somente em poucas é indicada alguma circunstância capaz de viabilizar uma datação mais exata. Na edição espanhola, mostram-se as datas e lugares aproximados, fruto das reflexões dos especialistas, como Altaner, Walz e Scheeben.

As cartas de Jordão que conhecemos foram escritas em latim. Salvo as de caráter mais oficial, voltadas para toda a Ordem ou para os frades do convento de Paris, ao menos na forma como foram transmitidas, as epístolas são, em geral, breves. As eventuais cartas recebidas por Jordão não foram preservadas. No entanto, fica evidente pelo conteúdo das missivas que, em muitos casos, ele apenas respondia a uma correspondência recebida.

\footnotetext{
${ }^{7}$ Como o maior número de cartas são dirigidas à Diana de Andaló e às monjas do convento de Santa Inês, as notícias sobre a transmissão deste conjunto são mais abundantes. Os autores afirmam que elas foram transmitidas por vários manuscritos, que apresentam algumas variantes. O mais antigo data do século XV. Ele foi mantido no Convento de Santa Inês até 1796, quando a casa foi destruída. Posteriormente, ficou guardado no Mosteiro de São Domingos e São Sixto. Desde 1931 está no convento de Santa Maria do Rosário de Monte Mario, Roma. A carta 51, dirigida a Diana, foi transmitida por outro códice, o Codex Herbipolensis (DEL CURA, 1984, p. 8).
} 
Quanto ao estilo adotado, se nas cartas dirigidas aos irmãos o tom é mais formal, nas escritas para as religiosas é imediato e diáfano. A despeito de sua formação intelectual, não notamos com clareza o respeito às normas das ars dictaminis nas missivas enviadas às monjas. Uma explicação para esse fato pode estar na transmissão. Como as epístolas foram transmitidas em bloco, é possível que possam ter passado por uma edição, na qual os elementos fixos foram suprimidos. Outra possibilidade interpretativa seria o uso deliberado do tom pessoal e informal, que objetivava, sobretudo, a troca de informações e o aconselhamento espiritual das monjas.

A despeito do valor histórico das epístolas redigidas por Jordão para o conhecimento de diversos aspectos referentes às primeiras décadas de organização da Ordem dos Pregadores, sobre tais documentos, como aponta Alberzoni, "has not been given adequate scholarly consideration" (2010, p. 3). Neste sentido, encontramos somente um trabalho que se aproxima de nossa abordagem. Trata-se de um artigo de autoria da própria Alberzoni, intitulado Jordan of Saxony and the Monastery of St. Agnese in Bologna, publicado em 2010. Neste trabalho, apesar de analisar a correspondência de Jordão enviada para Diana e suas irmãs, a autora centra a sua discussão no vínculo jurídico do convento de Santa Inês com a Ordem dos Pregadores e, para tal, analisa outros documentos além das epístolas, tais como a Vita dedicada a Diana de Andaló.

\section{A questão da vida religiosa feminina nos séculos XII e XIII}

A historiografia tem apontado que, no bojo das transformações que marcaram o Ocidente nos séculos XI e XIII, cresceu significativamente o número de mulheres que desejavam abraçar a vida religiosa. ${ }^{8} \mathrm{~A}$ par deste crescimento, houve a preocupação, por parte da Igreja Romana, de normalizar tal movimento.

\footnotetext{
${ }^{8}$ Sobre o tema ver, dentre outros LECLERQ (1980); SCARAFFIA, e ZARRI (1994); BENVENUTI PAPI (1983 e 1990) e BOLTON (1976 e 1990).
} 
Neste sentido, o tema foi alvo de deliberação nos concílios lateranenses II, III e IV presididos pelo papa, 9 como é possível constatar pelas atas dessas reuniões. ${ }^{10}$

Além dessas normativas de caráter mais geral, podemos destacar as que foram elaboradas de forma específica para as mulheres que desejam viver comunitariamente e em pobreza na região da Lombardia e Toscana pelo então legado papal Hugolino Segni, futuro Gregório IX. O legado fora autorizado por Honório III, em 1218, a submeter comunidades femininas diretamente à Santa Sé, tornando-as isentas de qualquer intervenção eclesiástica ou laica local. ${ }^{11}$

A fim de regulamentar a vida religiosa dessas mulheres, Hugolino impôs a obediência à Regra de $\mathrm{S}$. Bento e a uma forma de vida que ele mesmo elaborou, a fim de adaptar as normas beneditinas para uma casa feminina. Este documento, que é conhecido hoje como Forma de Vida de Hugolino, aborda diferentes temas: a entrada no mosteiro; a observação do Ofício divino; o estudo; o silêncio; o jejum; o cuidado com as doentes; a vestimenta; a clausura; a guarda da porta e o relacionamento com os externos à comunidade, os capelães e os visitadores. Posteriormente, essas normas foram instituídas em diversas outras comunidades femininas do Ocidente que desejavam viver como pobres e reclusas. ${ }^{12}$

Outra evidência da preocupação papal em normalizar a vida religiosa feminina está na iniciativa surgida com Inocêncio III de reformar as casas femininas de Roma. Segundo Brenda Bolton, que estudou os problemas pelos quais passavam

\footnotetext{
${ }^{9}$ Esse tema é desenvolvido em FRAZÃO DA SILVA (2008. v. 1. p. 1-9).

${ }^{10}$ Latrão II foi realizado em 1139, e nesta assembleia institui-se, no tocante às religiosas, que as monjas que contraíssem matrimônio deveriam ser separadas de seus esposos (cânone VIII); as mulheres que desejassem seguir a vida religiosa ficariam obrigadas a adotar uma das regras então reconhecidas pela Igreja Romana - São Bento, São Basílio ou Santo Agostinho; ficava vetada a residência de mulheres religiosas em prédios separados do restante da comunidade (cânone XXVI), e os coros mistos foram proibidos (cânone XXVII). O tema continuou a ser alvo de atenção no III Concílio de Latrão, ocorrido em 1179. Nas atas, encontramos as seguintes normas: o celibato eclesiástico foi reafirmado para todos os religiosos, incluindo as monjas (cânone XI), e as visitas às comunidades femininas só deveriam acontecer em situações de necessidade e com motivo suficiente (cânone XI). O Lateranense IV, reunido em 1215, deliberou sobre a vida religiosa em geral, instituindo a obrigatoriedade da realização periódica de capítulos e das visitas para correção disciplinar (cânone XII), bem como a proibição do surgimento de novas ordens e da elaboração de regras (cânone XII), dentre outros temas. ${ }^{10}$ No cânone LXIV, é condenada a simonia entre as monjas e monges, enfatizando, porém, os "erros" das mulheres.

${ }^{11}$ Assim, já em 1219, quatro comunidades foram colocadas sob a direção papal: Santa Maria de Monticelli, em Florença; Santa Maria de Monteluce, em Perúgia; Santa Maria de Gattaiola, em Lucca, e Santa Maria fora da Porta Camollina, em Siena.

12 Uma análise sistemática desta Forma de Vida foi publicada por FRAZÃO DA SILVA (2016. p. 185-203).
} 
os conventos daquela cidade, eles eram pequenos e relativamente pobres. As abadessas geralmente tinham que vender as propriedades das comunidades para a sobrevivência do grupo, às vezes aconselhadas por suas famílias ou por pessoas que desejavam lucrar com tais transações (BOLTON, 1990, p. 107-108). Neste sentido, Inocêncio III conseguiu bloquear tanto a venda de propriedades quanto a interferência das famílias. Ele também agrupou todas as religiosas em uma só comunidade para viverem em clausura e buscarem a autossuficiência financeira, conferindo aos gilbertinos ${ }^{13}$ a missão de zelar pelo grupo (SMITH, 2009, p. 347348).

Em um primeiro momento, a missão de cuidar das religiosas foi conferida aos gilbertinos. Fundada no século XII, essa ordem vinculava-se ao ideal da vita apostolica e aceitava freiras enclausuradas. No entanto, em novembro de 1219 os gilbertinos se desligaram do projeto, alegando que os recursos que o papa colocara à sua disposição não foram suficientes para manter as instalações das religiosas (BOLTON, 1990, p.111).

Honório III deu prosseguimento ao plano de seu antecessor, a fim de regular e homogeneizar a vida religiosa feminina no centro da Cristandade, Roma. Mas como os gilbertinos não foram bem-sucedidos em sua tarefa, o papa se voltou para o Fundador da Ordem dos Pregadores, como relata Cecília de Roma em sua Relação dos Milagres realizados por Santo Domingos em Roma (1947, p. 463).

Para executar a missão que lhe fora confiada, Domingos foi auxiliado, dentre outros, pelo então cardeal Hugolino, futuro Gregório IX que, como já apontamos, formou a Ordem das Damas Pobres, submetendo várias comunidades femininas da Lombardia e Toscana diretamente a Roma, elaborando para elas uma forma de vida. De acordo com o relato de Cecília de Roma, as freiras que concordaram com o projeto fizeram novamente os votos e se transferiram para S. Sisto, assentindo em não deixar

${ }^{13}$ Fundada no século XII, essa ordem vinculava-se ao ideal da vita apostolica e aceitava freiras enclausuradas. 
a clausura. Assim, o referido convento feminino de S. Sisto nasceu, portanto, vinculado a Domingos. ${ }^{14}$

Em todas essas iniciativas verificamos que, se por um lado, existia uma preocupação em regulamentar a vida religiosa feminina, por outro, esta mesma normatização buscava retirar das mulheres a possibilidade de sair das suas comunidades para conseguir seu próprio sustento, ao impor a clausura, e de cuidar da direção espiritual umas das outras, colocando-as sob a dependência material e espiritual dos eclesiásticos. Assim, vários institutos religiosos, como os cistercienses e premonstratenses, começaram a se negar a incorporar comunidades femininas de forma permanente ou temporária, discutindo a questão em seus capítulos durante várias décadas do século XIII. ${ }^{15}$

Os frades pregadores também não ficaram imunes a tal discussão, como é possível rastrear por meio dos diferentes documentos. Os dominicanos pregavam para as mulheres, mas alguns resistiam fortemente a tomá-las como irmãs. É provável que, nos primeiros anos de organização do movimento, Domingos e seus seguidores se entendessem como um grupo de cônegos regulares (CANETTI, 1996, p 31). Como já existiam comunidades de cônegas estabelecidas no Ocidente e a missão de pregação itinerante ainda estava em formação para os primeiros irmãos, a fundação dos conventos femininos pode ter sido considerada como uma estratégia na luta contra a heresia. As mulheres foram, então, inseridas no grupo sob a forma de vida contemplativa e quatro comunidades foram organizadas, direta ou indiretamente, por Domingos: Prouille, em 1206; São Sisto, em 1220, Madrid, em 1220, e Santa Inês de Bolonha, em 1223. Entretanto, como destaca Alberzoni, a inserção de cada uma das comunidades de mulheres junto aos pregadores foi

\footnotetext{
${ }^{14}$ Segundo relata Cecília Romana, algumas monjas se arrependeram de seus votos sob a pressão dos familiares (1947, p. 481).

${ }^{15}$ Sobre o tema ver, dentre outros, ALBERZONI (1998) e BRUNELLI (1998).
} 
motivada por razões específicas, o que redundou em situações jurídicas distintas (2010, p. 11).16

É possível concluir, por meio dos testemunhos documentais, que, conforme a missão de pregação se desenvolvia e os contornos específicos da Ordem iam se tornando cada vez mais claros, o lugar das mulheres entre os frades começou a se colocar como um problema. Assim, nas primeiras décadas da história da Ordem, os irmãos pregadores se questionaram sobre qual era o vínculo jurídico entre as comunidades femininas e as masculinas; como dar assistência espiritual às mulheres, se muitos no século careciam da palavra, e, ainda, como sustentar as irmãs, posto que a Ordem era mendicante ${ }^{17}$ e as mulheres não poderiam deixar os conventos para esmolar devido a obrigatoriedade da clausura (PARISSE, 1994, p. 196).

Segundo Micheline de Fontette, pautada em Mortier, já em 1224, em um capítulo celebrado em Paris, ficou decidido que as novas fundações de comunidades femininas ficariam suspensas. Segundo a autora: "Certains frères voulaient même trancher le vif et exclure de l'ordre les maisons existantes! Le provincial de Lombardie parlait de retirer les féres de Saint-Agnés. Um cri d'angoisse s'eleva de tous les couvents féminins" (1967, p. 117). Segundo a mesma autora, na ocasião Jordão da Saxônia teria intervindo pelo convento de Santa Inês de Bolonha junto ao papa Honório III que, em 1226, emitiu uma bula reafirmando a filiação deste mosteiro aos dominicanos: "sub eodem ordine perpetuo permanere" (apud FONTETTE, 1967, p. 196).

\footnotetext{
${ }^{16}$ Para citarmos apenas dois exemplos, Prouille era uma comunidade de cônegas, o que a diferia da comunidade de S. Sisto, que estava sob a responsabilidade direta da Igreja Romana e era de caráter monacal.

${ }^{17}$ Os irmãos pregadores mantinham as suas casas por meio de recursos obtidos com a mendicância, portanto, a vida em comum era organizada de tal forma que alguns membros de cada convento eram responsáveis por buscarem recursos junto às comunidades próximas.
} 
Em seu estudo, Alberzoni não menciona a proibição de 1224, mas a bula de Honório III, Ad audientiam nostram. Ela afirma, porém, que o texto desse documento

confirms that a debate arose within the Order regarding the cura monialium for its sister after 1224. This debate focused on who constituted the female branch of the Order and which houses were juridically linked to the Order, for exemple St. Sixto and those who would obtain later papal aproval (ALBERZONI, 2010, p. 12).

No início da década de 1220, dentre os quatro mosteiros femininos vinculados a Domingos, só S. Sisto teria um estatuto jurídico definido por estar sob a proteção de Roma, situação que provavelmente foi alcançada também por St. Inês em 1226, a partir da referida bula de Honório. Mas a proteção do papado equivalia uma vinculação formal aos Pregadores?

Concordamos com Mercedes Pérez Vidal quando esta afirma que a filiação de comunidades femininas, até 1228, “se llevó a cabo de forma heterogénea, sin un patrón claro, sin contar en muchos casos com la aprobación previa o a posteriori de las autoridades y organismos centrales de la Orden” (2013, p. 137). Foi justamente neste contexto de indefinição jurídica da vinculação das comunidades femininas aos dominicanos que, no Capítulo Geral de 1228, realizado em Paris, pela primeira vez foi proibida a fundação de novas casas de mulheres. ${ }^{18} \mathrm{O}^{\prime}$ Connor transcreve o decreto:

Em nome da obediência e sob pena de excomunhão, nós formalmente proibimos a todos os irmãos que operem de qualquer forma para que as monjas ou comunidades de mulheres religiosas de qualquer tipo sejam admitidas no cuidado da Ordem. Ao mesmo tempo proibimos qualquer um de receber qualquer mulher ao hábito ou fazer profissão. (O'CONNOR, 1916, p. 115) ${ }^{19}$

\footnotetext{
${ }^{18}$ Não há, ao menos no epistolário preservado, nenhuma repercussão desta possível proibição do Capítulo parisiense de 1224 nem da bula papal. Alguém pode argumentar que as cartas datadas de 1229, na verdade, se referiam à proibição de 1224 , não a de 1228 . Contudo, se adotarmos a hipótese de Gelabert e Milagro (1947, p. 236-237 e p. 246-247), de que Estevão de Espanha só assumiu o cargo de Provincial em 1227, a datação das cartas deve ser, de fato, posterior a da realização do Capítulo de 1228.

19 "In the name of obedience and under penalty of excommunication, we formally forbid any of the brethren to arrange in any way for nuns or communities of religious women of any sort to be committed to the care of the Order. And at the same time we forbid any one to receive any woman to the habit or to profession." (O'CONNOR, 1916, p. 115).
} 
Éjustamente a repercussão dessa normativa - as dúvidas geradas, as distintas interpretações e as tensões no seio da Ordem - que passamos a discutir a partir das epístolas selecionadas.

\section{Relações de poder e escrita epistolar}

Como já destacamos, dentre o conjunto de cartas escritas por Jordão, escolhemos três que consideramos relevantes para problematizar o que foi o debate sobre a constituição do braço feminino da Ordem dos Pregadores. Assim, centramos nossa análise nas epístolas de número 47 e 48, remetidas a Diana, e 49, enviada a Estevão de Espanha, segundo a edição de Altaner.

Como as cartas tão enfaticamente apontam, Jordão e Diana desenvolveram um laço de amizade, baseado na identidade de ideais religiosos. Se adotarmos a hipótese de que Jordão, de fato, provem de uma família nobre da Saxônia, isso o aproximaria de Diana também em termos sociais, já que ela era de uma parentela abastada e detentora de poder político em algumas cidades da Lombardia. Essa amizade, alimentada pela troca de cartas e, provavelmente, por visitas eventuais, como é possível concluir do conteúdo das missivas, constituiu um elo entre ambos que foi além da obrigação da cura monialium ou da relação institucional entre uma religiosa e o Mestre Geral da Ordem Dominicana.

Foi esse laço de amizade que provavelmente motivou a redação da carta 48. Ela é datada do verão de 1229, foi enviada de Gênova e endereçada apenas à Diana. Jordão, certamente, respondia a uma demanda da monja pois, depois da salutatio, escreve: "A tua inquietude por causa da constituição de que me falas na tua carta mais me parecem mexericos e medo desnecessário” (2014, p. 66). Parece-nos que, com esse início, Jordão está repreendendo Diana, pois, segundo a sua perspectiva, ela havia exagerado na reação às notícias do Capítulo Geral de 1228, acima mencionado, demonstrando, no mínimo, falta de confiança na liderança do próprio amigo. 
Como já sublinhamos, nessa assembleia decidiu-se pela não filiação de novas comunidades femininas à Ordem e pela recusa da consagração de mulheres à vida religiosa. Certamente essa notícia deixou as monjas das casas já fundadas preocupadas e em dúvida quanto a sua vinculação formal à Ordem dos Pregadores. Sem uma afiliação jurídica concreta, qual seria o destino daquelas mulheres? Sob o governo espiritual de quem viveriam? Seriam delegadas ao bispo, como acontecia com tantas casas femininas? Em qualquer uma das hipóteses haveria, no mínimo, uma transformação não só na forma de vida, mas também de status, redundando em preocupação quanto à segurança material dessas comunidades.

A fim de sanar essas dúvidas, Jordão continua a sua epístola esclarecendo que: "Nesta constituição nunca entendemos, nem eu nem os Definidores, que estavam incluídas as monjas da nossa Ordem” (RODRIGUES, 2014, p. 66). Para afiançar essa resposta, o Mestre Geral expõe o seu papel nas decisões: "Disto não tenho nenhuma dúvida, porque intervim em todos os Capítulos e definições e conheço as causas de todas as constituições que, até agora, promulgámos” (RODRIGUES, 2014, p. 66). E esse papel, é claro, estava fundamentado em sua autoridade como líder da Ordem.

É baseado nesta autoridade que Jordão passa a expor para Diana, e ao público potencial da carta, a sua interpretação e explicação para a decisão tomada. A norma não objetivava atingir "nossas monjas", mas as "mulheres estranhas à Ordem", que estavam sendo recebidas “com grande facilidade” (RODRIGUES, 2014, p. 66) por alguns frades.

Como é possível perceber pelas demais cartas, Jordão dava importância à entrada de novos membros na Ordem, pois, via de regra, fornece informações sobre os que eram incorporados. Ou seja, ele sabia que a Ordem crescia a olhos vistos. Assim, podemos argumentar: como ele não esperava que o instituto também fosse atrativo para as mulheres? Sem dúvidas, as quatro casas femininas que existiam até o Capítulo de 1228 não seriam suficientes para receber todas aquelas que, muito 
provavelmente, já buscavam a liderança espiritual dos dominicanos em diversas regiões do Ocidente. Como Jordão se posicionava perante essa questão?

A historiografia que aborda a história inicial dos Pregadores, muito embora pouco extensa e abordando a temática de forma superficial, ${ }^{20}$ aponta que o Mestre Geral era partidário da entrada das mulheres na Ordem. No entanto, a carta em questão não defende essa perspectiva, só esclarece que a filiação de novas comunidades femininas fora suspensa e que as antigas - Prouille, Madri, São Sisto de Roma e Santa Inês de Bolonha -, tradicionalmente vinculadas ao próprio Fundador, e que Jordão chama de “nossas monjas”, seriam mantidas.

Por meio desta carta enviada a Diana, percebemos que Jordão não aborda, de fato, a questão da presença de mulheres na Ordem nem propõe uma solução alternativa para incorporar aquelas que desejavam seguir o ideário dominicano. Ao contrário, ele realça que ocorria, então, um certo descontrole ao incorporar mulheres ao Instituto, justificando, assim, o decreto.

De fato, ao destacar que o problema que o Capítulo desejava sanar era a presença de “mulheres estranhas à Ordem”, ou seja, aquelas que não pertenciam a nenhum dos quatro mosteiros já reconhecidos, ele criava uma hierarquia entre aquelas que desejavam seguir a forma de vida dominicana. Uma hierarquia, é importante sublinhar, que não se fundamentava unicamente no sexo, mas em um elo que outrora fora estabelecido entre algumas mulheres, Domingos de Gusmão e seus primeiros seguidores. Parece-nos, portanto, que Jordão não defendia a presença de mulheres na Ordem. Ele aceitava manter as comunidades já reconhecidas, como Santa Inês, talvez até por obediência a uma decisão papal, se considerarmos a bula de Honório III transcrita por Fontette, mas parece partilhar da visão hegemônica do Capítulo de 1228: a Ordem dos Pregadores não deveria incorporar novas mulheres.

\footnotetext{
20 De fato, são poucas as obras dedicadas à história da Ordem dos Pregadores. A última grande obra de síntese foi feita pelo frade Hinnebusch (1966-1973).
} 
Em sua epístola, usando um tom ao mesmo tempo autoritário e conciliatório, Jordão ressalta que para Diana e suas irmãs nada mudara, ainda que, a partir daquele momento, dezenas de mulheres tenham sido excluídas ou impedidas de ingressar no Instituto. Ele ainda pede que o assunto não seja tratado com ninguém e aconselha que a monja se mantenha em segurança.

Em seguida, o Mestre Geral faz um comentário: “Com grande indiscrição procedeu quem te suscitou esta dúvida, com a intenção de te atemorizar no que nada havia a temer" (RODRIGUES, 2014, p. 66). A partir dessa afirmação, podemos traçar duas possibilidades: Diana soube da decisão de 1228 e procurou alguém para ter mais esclarecimentos a respeito da presumida desvinculação da Ordem ou alguém foi até ela apresentando essa possibilidade. Qualquer uma dessas hipóteses aponta para uma circulação de notícias no interior da Ordem que colocava "em xeque" a autoridade do Mestre Geral. Assim, o texto da carta parece demonstrar que Jordão estava contrariado com o fato de que as informações e interpretações que corriam sobre as decisões do Capítulo Geral estavam trazendo dúvidas e temor, o que não só afetava a sua autoridade de líder, mas também o seu papel de guia espiritual para Diana e outras mulheres religiosas.

Jordão prossegue a carta exortando Diana a viver "com confiança e alegria" (RODRIGUES, 2014, p. 66), isto é, sem preocupar-se com as questões institucionais. Ele ainda aconselha a monja a preencher com Cristo a ausência deixada por ele. Finaliza a missiva declarando que a rotina do convento deveria ser mantida, já que nada mudara:

As monjas que tinham de professar, podem fazê-lo com toda a tranquilidade nas mãos da Prioresa ou do Prior conventual ou do Provincial, em meu nome e, com isso, alegrar-me-ei como se professassem nas minhas mãos. Que não tenham nenhuma dúvida acerca da sua validade (RODRIGUES, 2014, p. 66).

Ou seja, o tom usado por Jordão na carta a Diana é o da autoridade que esclarece e consola, mas que não dá espaço para a livre manifestação. A monja 
deveria ouvir a explicação do Mestre Geral, aceitá-la, e não voltar a comentar o assunto com ninguém. É um tom que também não permitia a discussão da questão mais ampla da incorporação das mulheres pela Ordem, tratando somente do caso específico de Santa Inês.

Foi no mesmo momento em que escreveu a Diana, que Jordão, provavelmente, dirigiu uma epístola ao provincial da Lombardia, Estevão de Espanha. A missiva também é datada do ano de 1229, a sua composição é situada em Gênova, cidade da qual foi remetida a carta para Diana, e aborda o mesmo assunto.

Na leitura desta epístola, um aspecto se destaca: ao contrário da missiva enviada à Diana, Jordão se dirige a Estevão não com um tom de esclarecimento ou consolo, mas de correção. O Mestre Geral assume uma postura professoral para ensinar ao provincial da Lombardia qual deveria ser o procedimento correto da liderança da Ordem.

O tom de irritação perceptível no início da carta enviada a Diana aparenta elevar-se consideravelmente nesta outra epístola, mais longa do que a anterior. Ao menos na versão transmitida do texto, ele inicia a missiva sem preâmbulos, acusando o provincial de ter uma "consciência assustada": "vejo que a sua consciência se assustou com o barulho da folhagem” (RODRIGUES, 2014, p. 67). Como Mestre Geral, Jordão se entende na posição de perscrutar as almas de seus governados e indicar seus erros. E ao diagnosticar a consciência de Estevão como “assustada”, logo na primeira linha de sua carta, revela conhecer as intenções do Provincial.

Jordão afirma que um erro foi cometido: Estevão “achou que tinha sido promulgada contra as monjas de Santa Inês a constituição que proíbe aos frades receberem das mulheres a tonsura dos cabelos, a tomada de hábito e a profissão” (RODRIGUES, 2014, p. 67). Segundo o Mestre Geral, essa falta não residia somente na incorreta interpretação da constituição, mas também no fato de que essa 
interpretação acabou por perturbar as irmãs de Santa Inês, o que é classificado na epístola como algo que não é de Deus, pois gerou uma questão inútil.

Jordão prossegue a carta, dando a sua interpretação sobre o "verdadeiro" sentido da referida constituição:

\begin{abstract}
essa constituição só se refere àqueles frades que, nalgumas províncias, como a Teutónia e outras que, nas suas missões apostólicas, recebiam facilmente a tonsura, a tomada de hábito e a profissão de prostitutas e raparigas muito novas, que queriam converter-se à penitência ou consagrar-se ao Senhor com voto de castidade (RODRIGUES 2014, p. 67).
\end{abstract}

Se compararmos essa passagem à de mesmo teor que figura na carta para Diana, percebemos que naquela não há menção ao local, origem da proibição, ou à atividade das mulheres que pretendiam entrar na Ordem. Nela, Jordão se refere apenas a "mulheres estranhas à Ordem/ mulheres determinadas" (RODRIGUES, 2014, p. 66). Essa ausência de detalhes pode se relacionar ao fato do Mestre Geral considerar que Diana não precisava saber das minúcias porque não estava envolvida na administração da Ordem; ou porque os pormenores da questão simplesmente não lhe concernissem, devido a sua posição inferior como uma mulher religiosa, ou, ainda, porque Jordão quisesse poupá-la de informações que considerava desconcertantes para uma monja filha de família abastada.

Se os detalhes não eram importantes para Diana, em relação a Estevão, Jordão parece considerar que era necessário evidenciar que estava a par de todo o ocorrido. Ao demonstrar conhecimento sobre a situação, o Mestre busca reafirmar a sua autoridade: “Conheço perfeitamente os factos, as ordenações e as intenções de todos os Capitulares. E sei que na promulgação dessa ordenação não houve nem uma palavra nem intenção alguma em relação às monjas da Ordem” (RODRIGUES, 2014, p. 67).

Jordão afirma conhecer o ocorrido com perfeição: não lhe escapava qualquer informação, fosse ela de natureza factual, jurídica ou mental. Logo, não seria dobrado à outra interpretação ou mesmo a rumores infundados. A necessidade de 
atestar todo esse vasto conhecimento pode ter sido elaborada não somente para responder a uma interpretação equivocada, mas a um possível questionamento de sua autoridade e firmeza por parte de Estevão. Mas Jordão vai além, pois parece querer afirmar o domínio que tinha sobre a Ordem e cada um de seus membros. Assim, além de conhecimento, ele também declara ter controle sobre a situação pois, em última instância, tinha autoridade para revertê-la por ter sido eleito pelo grupo. Ao menos é o que podemos interpretar pela frase: "se alguém pensa que não tenho autoridade para dispensar das regras da Ordem, o mesmo é pensar que não me devia ter sido confiado o cargo de Mestre Geral” (RODRIGUES, 2014, p. 67).

Ao afirmar que Estevão não reconhecia a sua autoridade como Mestre Geral, Jordão busca demonstrar que o Provincial também não aceitava a sua eleição para o cargo. Ou seja, ele não só deixa novamente patente a sua autoridade como realça que quem a questiona também põe em dúvida a própria decisão coletiva de elegê-lo como Geral. Desta forma, uma possível contestação de sua autoridade por Estevão seria como uma crítica a toda a Ordem reunida em Capítulo.

Jordão continua a sua argumentação: "Mas admitamos que quereríamos decretar uma coisa dessas. Teríamos direito a fazê-lo? De modo nenhum. Teríamos agido contra a vontade do Papa, por cujo mandato estamos obrigados a atender às monjas, e também aos outros frades da Ordem” (RODRIGUES, 2014, p. 67).

O Mestre Geral sustenta a sua interpretação e autoridade na do papado: a liderança da Ordem deve seguir as ordenações papais e ser responsável tanto pelos irmãos quanto pelas irmãs. Desta forma, Jordão determina que não pode haver qualquer dúvida sobre o pertencimento das monjas de Santa Inês à Ordem e, portanto, Estevão deve parar de suscitar problemas. Afinal, os pregadores devem estar de acordo e não demonstrar qualquer incerteza. Fazia-se necessário, portanto, cerrar fileiras, atestar a harmonia da comunidade nascente e já eivada de contradições. Por isso a assertividade de Jordão, que toma lugar de máxima autoridade, subjugando, assim, aquele que o contesta. 
Se a primazia do Mestre ainda não estava clara, ela se torna indubitável no trecho subsequente: "Não há nas Constituições nada tão grave, para cuja dispensa não me tenha sido outorgada autoridade, tendo em conta as necessidades das pessoas, do lugar e do tempo e conforme julgue conveniente” (2014, p. 67). Jordão faz então um desvio para destacar que, dentre todas as normas, só três artigos não poderiam ser revogados nem poderiam admitir dispensa. Mas, para estes, como ele mesmo esclarece, foi pedida a confirmação da Santa Sé. Mais uma vez a autoridade papal é invocada para sustentar a do Geral.

A seguir ele sublinha: "Sobre todas as outras coisas, não tenho dúvida nenhuma de que estão confiadas ao meu poder de dispensar" (RODRIGUES, 2014, p. 67). Escusado o coloquialismo, aqui Jordão, em outras palavras, diz: “Quem manda aqui sou eu!”. A veemência desse trecho ainda faz referência à questão das monjas, mas pode, igualmente, aludir a outro assunto também contestado por Estevão, não explicitado na carta.

Desde o início da formação da regra de vida dos frades, as Constituições, um de seus traços mais característicos foi o uso de dispensas, ou seja, as permissões dadas, geralmente pelo Mestre Geral, para que não se cumprissem as regras estabelecidas em casos específicos. ${ }^{21}$ Como a alusão às dispensas é muito frequente nas atas dos Capítulos Gerais, provavelmente esse era outro ponto de conflito interno à Ordem, especialmente porque davam ao Mestre Geral um mecanismo útil tanto nas negociações quanto nas imposições e que poderia ser usado de forma excessiva.

Mas Jordão não para aí. Ele continua a justificar as dispensas que instituiu fundamentando-se em sua própria consciência: "Graças a Deus, não me inquieta a consciência de, até ao presente, em nada ter concedido dispensa que não tivesse a maior das seguranças em poder fazê-lo" (RODRIGUES. 2014, p. 67). Em contrapartida, acusa o seu destinatário de inconstante, exortando-o "a ser mais firme nas suas ideias, já que não é sinal de muita segurança mudar constantemente de

${ }^{21}$ Até o momento em que a carta em tela foi escrita, as dispensas eram conferidas apenas por motivo de estudo. 
parecer por causa dos diferentes sentidos das palavras que ouvimos" (RODRIGUES, 2014, p. 67).

Esta argumentação de reforço à sua autoridade não se verifica na carta enviada a Diana. A explicação pode não estar no fato de ela ser mulher, mas por não ser vista como uma ameaça a Jordão ela não tinha destaque na liderança da Ordem²2 e, sobretudo, não contestava a autoridade do Mestre Geral, como, provavelmente, Estevão fazia.

É importante ressaltar que Estevão e Jordão tinham perfis muito similares. Como já afirmamos, Estevão recebera o hábito diretamente das mãos de Domingos, em 1219, quando era estudante de Direito em Bolonha. Ele estava presente no Capítulo de 1220, considerado como fundador das Constituições dominicanas. Foi provincial da Lombardia nas décadas de 1220 e 1230 e chegou a arcebispo. A carreira do hispano, portanto, não foi isenta de glórias.

Jordão, como Estevão, também havia conhecido Domingos em 1219 e no mesmo ano ingressado na Ordem. Também esteve presente no Capítulo de Bolonha, em 1220. Em 1221, é apontado pelo Capítulo como provincial da Lombardia, cargo que ocupou por poucos meses, já que foi indicado para ser Mestre Geral após a morte de Domingos, em agosto do mesmo ano.

Jordão foi alçado ao posto de Mestre Geral, mas quais aspectos o distinguiam e explicavam tal escolha, ou melhor, que justificavam a sua eleição em detrimento da opção pelo próprio Estevão? Jordão não havia ensinado em Paris, embora tenha obtido ali o grau de mestre, ou em qualquer outra universidade, o que poderia tê-lo colocado em evidência. Também não havia ocupado o provincialato por tempo suficiente para que seu governo se destacasse de alguma forma. O fato é que Jordão foi escolhido como Mestre Geral, Estevão não. Certamente a escolha do grupo por um nome em detrimento de outros se relaciona a diversos aspectos que seria

\footnotetext{
${ }^{22}$ Vale destacar que o papel de liderança na Ordem era negado a Diana pelo fato de ela ser mulher.
} 
impossível para nós rastrear, sobretudo o fato de se identificarem com grupos e ideias divergentes no seio da Ordem. Mas é lícito imaginarmos que, tendo Estevão e Jordão percursos semelhantes, houvesse entre eles certa competição.

Se Jordão era o Geral, não podemos esquecer que Estevão ocupava uma função central para a Ordem, o governo da maior, mais rica e influente província dominicana em um momento de consolidação do Instituto, o que, por si só, já seria motivo de tensão entre os dois frades. O tom autoritário da carta de Jordão corrobora a hipótese de uma disputa de poder dentro da Ordem que vai além da questão da admissão das casas femininas e revela que a eleição do Geral não o isentou de receber críticas e de ter sua autoridade questionada por alguns irmãos.

A carta remetida a Estevão, como a anterior, não trata da filiação das comunidades de mulheres à Ordem em geral, mas aborda de forma específica as dúvidas suscitadas nas irmãs de Santa Inês a partir do decreto de 1228. Parece, como já assinalado, que a principal preocupação de Jordão ao redigir essa missiva, bem como a enviada a Diana, era reafirmar a manutenção da adesão daquela casa sobre a qual o Provincial, como líder da região que abarcava também a cidade de Bolonha, centro nevrálgico da Ordem, também tinha autoridade. E, para tal, parece-nos que o mestre precisou mostrar ao provincial que a sua própria autoridade precedia a do hispano.

Assim, após reafirmar sua autoridade para conceder dispensas, Jordão retorna ao tema central da carta e ordena: “Às monjas de Santa Inês faça-as regressar do medo à total segurança/confiança” (RODRIGUES, 2014, p. 67). Esse trecho parece apontar que Estevão foi a causa dos temores de Diana, ou seja, ele, ou alguém a ele subordinado, é que teria comunicado às religiosas a sua interpretação sobre a decisão do Capítulo, o que teria gerado a dúvida entre as irmãs. Com esta ordem, Jordão, fundamentando-se na sua autoridade de Geral, buscava, portanto, reafirmar a ligação do convento de Santa Inês ao corpo da Ordem e colocar um ponto final no debate. 
Por quanto tempo Jordão foi capaz de se manter como autoridade na liderança da Ordem? Uma terceira carta, breve, datada de julho de 1234, também dirigida a Diana e escrita enquanto o Geral estava em viagem, pode nos dar algumas pistas. Após a salutatio habitual, o assunto é introduzido:

Depois de sair da Lombardia, fiquei doente em Trento e não pude assistir ao Capítulo Geral. Por isso, os Definidores não estavam muito ao corrente da situação da casa de Santa Inês e, ao não estar eu presente, decretaram qualquer coisa que vos é prejudicial (RODRIGUES, 2014, p. 65).

Jordão se refere, nessas poucas frases, ao Capítulo Geral de 1234, reunido em Paris, e que teve, entre suas resoluções, o endurecimento do que já havia sido decidido em 1228: além da proibição da afiliação de mulheres à Ordem, os conventos femininos mais antigos deveriam ser dela desligados. Como declara na carta, o Mestre, por estar doente, não pôde comparecer ao Capítulo em Paris, e, por isso, suas opiniões no que tange às monjas de Santa Inês foram ignoradas pela maioria do grupo, que tomou uma decisão contrária à sua.

A ênfase com que Jordão havia se dirigido à Estevão cinco anos antes, reafirmando a sua autoridade, à luz dessa informação, não parece assim tão descabida. O provincial da Lombardia certamente não era o único opositor do Geral nesta matéria. Havia uma resistência, certamente já generalizada no grupo, em se aceitar a cura mulierum quando este cuidado se traduzia em esforços administrativos e materiais. Os frades não se furtavam a pregar para as mulheres. Ao contrário, como é possível constatar pela documentação, essas eram alvo constante de seus sermões. Mas manter um mosteiro habitado por elas, que não podiam se entregar completamente à missão dos frades, que, cada vez mais, delineava-se como pautada nos estudos que conduziam à pregação, custava muito mais do que palavras.

Frente a essa oposição, Jordão novamente responde com firmeza e, mais uma vez, reafirma a sua autoridade: "Ao saber disto e, vendo o mal que estava feito, anulei tudo" (2014, p. 65). Nesta carta não há o tom de irritação que marca a de 1229 nem 
referências a uma luta de interpretações sobre o decreto, mas a preocupação em acalmar Diana, destacando que a normativa se tratava de uma "aflição momentânea" (2014, p. 65), que seria rapidamente dissolvida. Assim, depois de assegurar à monja que tudo seria resolvido, aborda assuntos costumeiros.

Esta missiva parece apontar para o fato de que o Mestre Geral estava, passados cerca de cinco anos, mais consciente das tensões internas da Ordem e de seu papel de autoridade para interpor-se a elas e manter o compromisso anteriormente estabelecido com as monjas de Santa Inês de Bolonha. A questão ganha novos contornos, pois não havia dúvidas sobre o que fora deliberado no Capítulo. Mas Jordão continua a reafirmar a sua autoridade, a despeito da decisão da maioria, ao declarar que anulara o decreto.

Não podemos esquecer que, como sublinhado acima, ainda que as negociações para a fundação do convento de Santa Inês tenham sido inicialmente estabelecidas entre Diana e Domingos, foi somente no governo de Jordão como Mestre Geral que a comunidade foi solenemente instalada. Desta forma, a luta de Jordão pela manutenção do vínculo desta casa feminina não deve ser compreendida,

como já afirmamos, como uma postura favorável à presença de mulheres na Ordem. Sua atitude, porém, deve ser interpretada à luz de seu cargo: ao reforçar os laços entre o convento feminino de Bolonha e os Pregadores, Jordão busca demonstrar, por um lado, que a sua autoridade era soberana e não poderia ser questionada, e por outro, que seus atos como líder do grupo - neste caso a fundação da comunidade não poderiam ser revogados, mesmo quando a visão da maioria mudara.

\section{Considerações finais}

Cientes da riqueza testemunhal das epístolas, por sua inserção na vida cotidiana, um importante meio de comunicação, os medievalistas têm buscado, há décadas, analisar tais materiais para o estudo de diversos aspectos da sociedade 
medieval. Entretanto, a despeito dos trabalhos já realizados, há muito a ser desenvolvido, sobretudo sobre o epistolário de Jordão que, face aos estudos sobre os seus demais escritos, ainda não foi suficientemente analisado.

Optamos por focar somente três cartas redigidas por Jordão e abordá-las pela perspectiva micro, atentas às relações sociais dos autores envolvidos, mas sem abrir mão da conjuntura mais geral vivida pela Ordem dos Pregadores e a Igreja Romana nas primeiras décadas do século XIII. E, dentre os muitos aspectos que poderiam ser debatidos, selecionamos o tema da filiação de comunidades femininas à Ordem. A nossa análise pontuou dois momentos: 1229 e 1234, mas o tema não foi alvo de debates só nessas datas. A questão já era discutida por diversas instituições religiosas desde o século XII e, após 1234, no seio da ordem dominicana. Neste sentido, novas tentativas de desvinculação das mulheres voltaram a acontecer em 1238, 1242 e 1252. O problema só foi resolvido em 1267, quando o papa Clemente IV finalmente estabeleceu um processo legal de afiliação (ASHLEY, 1990, p. 48), colocando as monjas dominicanas sob a jurisdição do Mestre Geral (HINNEBUSCH, 1975, p. 36).

Como assinalamos no decorrer do artigo, desde o início do século $\mathrm{XX}$, a historiografia insiste em ver nas cartas analisadas a tendência de Jordão em defender a presença de comunidades femininas no seio da Ordem dos Pregadores. Contudo, em nossa percepção, em momento algum, nem nas cartas aqui analisadas, nem nas outras, o Mestre Geral defende a existência de um braço feminino, mas apenas a vinculação aos pregadores das casas que haviam sido fundadas por Domingos e por ele próprio, como Santa Inês. Ou seja, Jordão estava apenas preservando o que fora anteriormente estabelecido, seja por iniciativa de Domingos ou por estímulo papal.

Como foi discutido, as missivas analisadas, apesar de abordarem a mesma temática, possuem estilos distintos. As cartas dirigidas a Diana são mais breves e o tom empregado é o de esclarecimento e consolo. A autoridade de Jordão é nelas referenciada, mas de modo sutil, pois não são apresentados nem discutidos detalhes 
institucionais. A epístola remetida a Estevão é mais detalhada. Nela fica patente o conflito em meio à liderança da Ordem. Há uma preocupação constante em sublinhar a autoridade do Mestre Geral, fundamentada em sua eleição pelo grupo e no papado, e que pode, inclusive, reverter, ainda que para casos isolados, as decisões do Capítulo.

Apesar de lacunares, as cartas revelam que, no seio da Ordem dos Pregadores, existiam perspectivas diferentes, que concorriam entre si, sobre como o instituto deveria se configurar. Tais posicionamentos distintos, no caso específico da presença de um braço feminino na Ordem, resultavam de um conjunto de elementos: o legado de Domingos; o compromisso da Ordem com o papado; a crescente ênfase na educação para a pregação; as dificuldades materiais, dentre outros fatores. Não havia, portanto, unanimidade sobre o tema. Alguns frades recebiam de braços abertos diversas mulheres; outros só consideravam como filiadas as irmãs das comunidades que haviam se unido à Ordem ainda sob a intermediação de Domingos, mesmo sem um estatuto jurídico claramente definido, e por fim, havia também aqueles que recusavam toda e qualquer vinculação com casas femininas.

Especificamente sobre Santa Inês, as missivas atestam que esta possuía uma situação especial por sua ligação com Domingos e Jordão, que foi reconhecida pelo papado. Assim, a despeito da aprovação, pela maioria dos representantes capitulares, de desvincular a referida comunidade da Ordem em 1234, Jordão usou de sua autoridade para reverter essa decisão.

As epístolas analisadas, portanto, revelam que a Ordem dos Pregadores, longe de formar um corpo unânime e coeso, foi marcada por tensões, disputas e negociações. Desta forma, percebemos que, por um lado, o Mestre Geral buscava afirmar-se como suprema autoridade na direção da Ordem, por outro, nem todos os frades reconheciam incondicionalmente a sua liderança e desenvolviam táticas para subvertê-la. 


\section{REFERÊNCIAS}

ALBERZONI, M. P. Clare of Assisi and the poor sisters in the XIIIth century.

Nova Iorque: Franciscan Institute Publications, 2004.

ALBERZONI, Maria Pia. Jordan of Saxony and the Monastery of St. Agnese in Bologna. Franciscan Studies, Nova York, v. 68, n. 1, p. 1-19, 2010.

ALBERZONI, M. P. Papato e nuovi ordini religiosi femminili. In: MENESTÒ, Enrico (dir.). CONVEGNO INTERNAZIONALE, 15., Assis, 1998. Atti.... Espoleto: Centro Italiano di Studi sull' Alto Medioevo, 1998. p. 207- 261.

ALESSANDRINI, Ada. Andalò, Diana D'. In: AA.VV. Dizionario Biografico Degli

Italiani. Roma: Istituto della Enciclopedia italiana, 1961. 82v., v. 3, p. 48-50.

ALTMAN, Janet Gurkin. Epistolarity: Approaches to a Form. Columbus: Ohio State University Press, 1982.

ASHLEY, Benedict. The Dominicans. Minnesota: Liturgical Press, 1990.

BEEBE, Thomas O. Writing Lessons: Representation Versus Rhetoric in the Ars

Dictaminis. In: BEEBE, Thomas O. (ed.). The Ideology of Genre. University Park, PA:

Penn State University Press, 1994. p. 66-111.

BENVENUTI PAPI, Anna et all. Temi e problemi nella mistica femminile trecentesca. Rimini: Accademia Tudertina, 1983.

BENVENUTI PAPI, Anna. In “castro poenitentiae": santità e società femminile nell'Italia medievale. Roma: Herder, 1990.

BOLTON, Brenda. Daughters of Rome: all One in Christ Jesus! Studies in Church History, Cambridge, n. 27, p. 101-115, 1990.

BOLTON, Brenda. Mulieres Sanctae. In: STUART, Susan Mosher (ed.). Women in Medieval Society. Philadelphia, University of Pennsylvania Press, 1976. p. 141-158.

BRUNELLI, Delir. Ele se fez caminho e espelho. Petrópolis: Vozes- FFB, 1998.

BYNUM, Caroline Walker. Jesus as Mother: Studies in the Spirituality of the High Middle Ages. Berkeley and Los Angeles: University of California Press, 1982.

CAMARGO, Martin. Ars Dictaminis Ars Dictandi. Turnhout: Brepols, 1991.

CANETTI, Luigi. Intorno all' "idolo delle origini". La storia dei primi frati pedicatori. In: MELO, G. (org.) I Frati Predicatori nel Duecento. Verona: Cierre Edizioni, 1996. p. 951. (Quaderni di Storia Religiosa, n. 3). 
CECÍLIA DE ROMA. Relación de los milagros obrados por Santo Domingo em Roma. In: GELABERT, M.; Milagro, J. M.; GARGANTA, J. M. (eds.). Santo Domingo de Guzmán visto por sus contemporáneos. Madrid: BAC, 1947. p. 451-494.

CHEREWATUK, Karen, \& WIETHAUS, Ulrike. Dear Sister: Medieval Women and the Epistolary Genre. Philadelphia: University of Pennsylvania Press, 1993.

CLASSEN, Albrecht. Female Epistolary Literature from Antiquity to the Present: An Introduction. Studia Neophilologica, Uppsala, v. 6o, p. 3-13, 1988.

CONSTABLE, Giles. Letters and Letter Collections. Turnhout: Brepols, 1976. (Typologie des sources du Moyen Âge occidental, fasc. 17)

DEL CURA, Alejandro OP. (ed.) Jordán de Sajonia. Cartas a Diana y a otras religiosas. Calaguera: OPE, 1984.

DERRIDA, Jacques. La Carte postale: de Socrate a Freud et au-delá. Paris: Flammarion, 2004.

FONTETTE, Micheline de. Les religieuses à l'âge classique du droit canon. Paris: Vrin, 1967.

FOUCAULT, Michel. História da Sexualidade: a vontade de saber. 13 ed. Rio de Janeiro: Graal, 1999.

FRAZÃO DA SILVA, A. C. L. Os concílios lateranenses e a vida religiosa feminina: reflexões sobre as normativas papais direcionadas às monjas nos séculos XII e XIII. In: XIII Encontro de História Anpuh - Rio, 2008, Seropédica. Anais Eletrônicos. Seropédica: UFRRJ, 2008. v. 1. p. 1-9. Disponível em:

<http://www.encontro20o8.rj.anpuh.org/resources/content/anais/1212952596_ARQUIV O_Anpuhregional_2008_AndreiaCLFrazaodaSilva_FINAL.pdf >. Acesso em: 11 dez. 2017.

FRAZÃO DA SILVA, A. C. L. Uma Leitura da Forma de Vida de Hugolino à luz da categoria gênero. In: MAGALHÃES, Ana Paula T.; LIMA, Marinalva Silveira. (Org.). Cotidiano, poder e relações sociais entre a Antiguidade e a Idade Média: Homenagem ao Professor Nachman Falbel. Maringá: EDUEM, 2016. p. 185-203.

GElabert, M.; Milagro, J. M.; GARGantA, J. M. (eds.). Santo Domingo de Guzmán visto por sus contemporáneos. Madrid: BAC, 1947.

GEORGES, Norbert. Blessed Diana and Blessed Jordan of the order of preachers; the story of a holy friendship and a successful spiritual direction. Somerset Ohio: Rosary Press, 1933.

HASELDINE, J. Friendship and Rivalry: the Role of Amicitia in Twelfth-Century Monastic Relations. Journal of ecclesiastical history, Cambridge, v. 44, n. 3, p. 390-414, 1993. 
HINNEBUSCH, W. History of the Dominican Order. Nova York: Alba House, 196673. $2 \mathrm{v}$.

HINNEBUSCH, William. The Dominicans: a short history. New York: Alba House, 1975.

HØGEL, C., BARTOLI E. (eds.). Medieval Letters. Between Fiction and Document. Turnhout: Brepols, 2015.

KELLY, Thomas A. F.; ROSEMANN, Philipp W. (org.). Amor amicitiae: on the love that is friendhip; essays in medieval thought and beyond in honor of Rev. Professor James McEvoy. Leuven: Peeters, 2004.

KONG, Katherine. Lettering the Self in Medieval and Early Modern France. Cambridge: D. S. Brewer, 2010.

LECLERCQ, Jean. Le genre épistolaire au moyen âge. Revue du moyen âge latin, Lyon, v. 2, p. 63-70, 1946.

LECLERQ, J. Il monachesimo femminile nei secoli XII e XIII. In: MENESTÒ, Enrico (dir.). CONVEGNO INTERNAZIONALE, 7., Assis, 1979. Atti.... Espoleto: Centro Italiano di Studi sull’ Alto Medioevo, 1980. p. 63-99.

MAGALHÃES, Alexandre F. Cartas para Diana Andaló e outras religiosas. Sta. Cruz do Rio Pardo: [s.n.], 2002.

MCEVOY, James. Notes On The Prologue Of St. Aelred Of Rievaulx's 'De Spirituali Amicitia,' With A Translation. Traditio, Cambridge, v. 37, p. 396-411, 1981.

MCNABB, Richard. To Father Juan, with Love, Bishop Alexander: Juan Gil de Zamora's Medieval Art of Letters. Rhetoric Review, Philadelphia, v. 23, n. 2, p. 103-120, 2004.

O' CONNOR, J. Saint Dominic and the Order of Preachers. New York: The Holy Name Bureau, 1916.

PARISSE, M. As Freiras. In: BERLIOZ, Jacques (org). Monges e Religiosos na Idade Média. Lisboa: Terramar, 1994. p. 185-200.

PEREIRA, Ana Paula Lopes. Deus Amicitia Est: Caridade e Amizade em Perspectiva Comparada. As vitae de beatas da diocese de Liège no século XIII face à Doutrina da Caridade na Patrística e na mística Cisterciense. Rio de Janeiro, 2013. 248 f. Tese (Doutorado em História Comparada) - Instituto de História. Universidade Federal do Rio de Janeiro.

PÉREZ VIDAL, Mercedes. Uniformitas vs diversitas en los monasterios femeninos de la Orden de Predicadores en Castilla (siglos XIII-XV). Territorio, Sociedad y Poder, Oviedo, n. 8, p. 133-152, 2013. 
RODRIGUES, Filipe, O. P. (ed.). Beato Jordão de Saxónia. Cartas à Beata Diana de Andaló. Lisboa: [s.n.], 2014.

SCARAFFIA, L. e ZARRI G., (ed.). Donne e fede: Santità e vita religiosa in Italia. Roma: Laterza, 1994.

SMITH, Julie Ann. Prouille, Madrid, Rome: the evolution of the earliest Dominican Instituta for nuns. Journal of Medieval History, Amsterdam, n. 35, p. 340-352, 2009.

VICAIRE, Marie-Humbert. Dominique et ses prêcheurs. Fribourg: Editions universitaires, 1977.

VICAIRE, Marie-Humbert. Saint Dominic and his Times. New York: MacGraw-Hill, 1964

VICAIRE, Marie-Humbert. Saint Dominique de Caleruega d'aprés lês documents de XIIIe. siècle. Paris: Du Cerf, 1955.

YSEBAERT, Walter. Medieval letters and letter collections as historical sources: methodological questions and reflections and research perspectives (Sixth-Fifteenth Centuries). Studi medievali, Espoleto, v. 50, n. 1, p. 41-73, 2009. 